\title{
Servicization of Product Lifecycle Management: towards Service Lifecycle Management
}

\author{
Fabien Mahut ${ }^{1}$, Matthieu Bricogne ${ }^{2}$, Joanna Daaboul ${ }^{3}$, Benoît Eynard ${ }^{4}$, \\ 1,2,3,4 Sorbonne universités, Université de Technologie de Compiègne, \\ Department of Mechanical Systems Engineering, UMR CNRS 7337 Roberval, \\ CS 60319, 60203 Compiègne Cedex, France \\ fabien.mahut@utc.fr, matthieu.bricogne@utc.fr, joanna.daaboul@utc.fr, \\ benoît.eynard@utc.fr
}

\begin{abstract}
Nowadays, many manufacturing industries are operating a process of servicization, id est the build-up of services to a product-centered offer. The implementation of service engineering into product-related activities requires a company to adapt to the new stakes on several levels, including strategic approaches and information systems. Therefore, Service Lifecycle Management (SLM), similarly to Product Lifecycle Management (PLM) might be defined as a way to take into consideration these new stakes, enabling management of services in a holistic approach dealing with service data and their structure. Products and services can benefit from information exchanges from one to another. In the aeronautic industry, several companies have shown the relevancy of information spreading between product and service activities in a bidirectional manner. A serviced product is thus designed considering the use stage and its service operations, which permits the collection of valuable information to improve design processes. Nevertheless, there are few research works on the convergence of the solutions brought out by SLM and PLM. This paper analyses how those two strategic approaches might coincide with the Information Systems's point of view in order to benefit from an effective interaction. A general analysis is presented at first. Then the paper focuses on the application of the paradigm of serviced products to the automotive industry.
\end{abstract}

Keywords : Product Lifecycle Management (PLM); Service Lifecycle Management (SLM); servicization; Product-Service-System; Information Systems

\section{Introduction}

In a challenging global market, hardened by economic, legislative and resources constraints, should a company strengthen its activity, it engages to transform its offers. In the case of manufacturing industries and concerning certain markets, offering a bundle of products and services has shown to be an economically relevant approach. This is presented as a way to achieve objectives such as risk reduction, competitiveness exposure reduction, and sustainability, through business model evolutions. This integration of products and services allows to improve customer loyalty and optimizes the balance between the offer and the customer's requirements, as it shapes the transaction from a punctual act of buying to a relationship-based transaction through a service [1]. The offer is more valuable for each of the customer 
and the provider, whom is naturally interested in extending materials reliability and lifespan, and managing maintenance as these costs are attributed to the provider himself $[2,3]$.

Literature dealt with these aspects throughout the concept of Product-Service System (PSS) in a paradigm which blurs the distinction between tangible products and intangible services under an integrated offer [4]. Historically associated with sustainability, PSS concept's main apparitions came from the Journal of Cleaner Production after Goedkoop's contribution in 1999 in a report concerned by sustainability [5]. PSS definitions are mainly centered around the keywords of "integrated bundle of products and services", and concerns directly the "consumer" or "customer" [2, 4-9], aiming at the achievement of "sustainability". This paper uses the definition presented by Mahut et al. (2015)[10].

The shift towards an integrated offer of products and services is illustrated by both concepts of productization and servicization (also found as servitization or servification), in a paradigm of a transition from a service or a product to a PSS [8]. It is noticeable that for both these integration processes, efforts are necessary to make products and services activities converging [11]. For manufacturing companies as car manufacturers, service is already a part of a company's activities. Some car manufacturers as GM, BMW and Toyota develop service networks, with for instance on-board diagnosis [12]. Nevertheless, the integration of service with products is often limited to after-sale services, and is still improvable. However, service development might not be identified as similar to product development, because of the differences concerning product lifecycles and service lifecycles. Furthermore, each service operation is unique and instantiated, whereas products are mostly considered in their serial definition.

The development and operation of products and services are mainly supported by Information Systems (IS). Software editors offer well known solutions for management of products all along their lifecycle, and are increasing solutions for management of services. Nevertheless these two kinds of IS solutions and their methodological and conceptual approaches seem not to be integrated enough. This barrier is seemingly due to the radical difference between products and service lifecycles. Indeed, the information managed during product-related activities and service-related activities is very different. Also, whereas most of the product activities concerns its development, service activities concerns the management of use-phase of an offer. This paper proposes to identify how product and service IS approaches can converge in order to reinforce he link between product and service development and management. A focus on interactions between lifecycle approaches is given and main stakes of integration are presented. In the second section of this paper, several lifecycle approaches for service integration with products are given. The third section endeavors to describe how two approaches for product and service management could interact, namely Product Lifecycle Management (PLM) and Service Lifecycle Management (SLM), are introduced. The fourth section uses the automotive industry case, and car manufacturers to look deeper into PLM and SLM convergence. 


\section{Service lifecycle approaches in the literature and relations with Product Lifecycle Management}

Services are a part of manufacturing companies' activities, and requires to manage information in order to be developed and operated. Its integration into lifecycle approach is studied hereafter with several strategies according to the way product and service activities converge.

Convergence of product and service activities is accessible through lifecycle management approaches. Product Lifecycle Management is defined as a "a holistic approach to the management of a Product" [13], supported by PDM applications which manage design and manufacturing information [14] with high expectations of interoperability with other IS of a company [15]. Service lifecycle concern appears in the literature, often correlated to PLM

\subsection{Service lifecycle is integrated as an extended part of the PLM.}

Lifecycle approaches for service emerged from the requirements of Maintenance, Repair and Overhaul (MRO) activities concerning complex systems with high operating reliability and safety constraints [16]. Previously, services have been handled with non-dynamic information coming from product development, poorly integrated with centralized business systems. Product Lifecycle Management aims at managing information in an integrated manner in a digital chain [17]. For services operated by MRO operators, the extension towards PLM allowed various results: reducing time of maintenance, enabling comprehensive relationship with customers and partners, and improving diagnosis [16, 18, 19].

Services from MRO operations are notably product-centered, and are consequently well integrated into a PLM approach, as part of technical PSS which emphasizes the content of technical services [20]. Nevertheless, it is not true for services in a generic definition which goes beyond MRO activities [21, 22]. An analysis based on Tukker's PSS classification [23] (see Error! Reference source not found.) highlights the relative importance of product-centered and service-centered approach for each kind of category. According to this figure, services in PSS are not necessarily productcentered, as for instance in the automotive industry: information delivery, navigation services, in-car entertainment, etc. These use-oriented and result-oriented emerging services integrated to a PSS offer might rather be developed and operated as servicecentered in completion with a product-centered approach. For these services, lifecycle

Fig. 1. Product-centered vs Service-centered approach based on Tukker's classification of PSS [23]

\begin{tabular}{|c|c|c|}
\hline \multirow{2}{*}{$\begin{array}{l}\text { Product-oriented } \\
\text { Services }\end{array}$} & 1.1. Product related service & \multirow{8}{*}{$\begin{array}{l}\text { Product- } \\
\text { Centered }\end{array}$} \\
\hline & 1.2. Advice and consultancy & \\
\hline \multirow{3}{*}{$\begin{array}{l}\text { Use-oriented } \\
\text { services }\end{array}$} & 2.1. Product leasing & \\
\hline & 2.2. Product renting or sharing & \\
\hline & 2.3. Product pooling & \\
\hline \multirow{3}{*}{$\begin{array}{l}\text { Result-oriented } \\
\text { services }\end{array}$} & 3.1. Activity management / outsourcing & \\
\hline & 3.2. Pay per service unit & \\
\hline & 3.3. Functional result & \\
\hline
\end{tabular}


phases, information type, and instantiation of the information differs tremendously from product activities, thus it is necessary to brake the conceptual framework given by a use of a PLM-based approach to manage services.

\subsection{Product-Service Lifecycle Management (PSLM)}

Wang et al. (2011) deals with service and product lifecycles as unified under one approach, namely the Product Service Lifecycle Management [2] proposed after Product and Service integration contributions [6, 24-26]. This approach enables effective collaboration between all the stakeholders of products and services lifecycle management. The coordination between different resources around the value chain is to be improved, as for networked participants and management activities of productservice lifecycle. This potential of improvement enabled by the PSS concept is associated with this integration $[6,20]$. Several methodologies are employed this way, often focusing on functional development in a first stage of development [27, 28]. Should this approach be more unified than services in PLM approaches, it challenges a company's organizational structure. The adoption of service activities for a manufacturing company and its managers is often difficult, because of the change in risk aversion due to ambitious objectives [29], which is in emphasis with a cultural product-service unification operated by a common approach. To answer this issue, Peruzzini et al. proposes a methodology to shift from Product to Product-Service Lifecycle Management, based on an analysis of a company's current situation and of its ecosystem's assets to achieve PSLM [30].

\subsection{Product Lifecycle Management and Service Lifecycle Management convergence}

The first approach found in the literature with services integrated to a PLM (presented in section 2.1) seems to be really efficient for product-related services, nevertheless the product-centered management of services prevents from a full management of all kind of services. The second kind of approach named PSLM (presented in section 0), unifying product and services under one common approach allows an effective collaboration of product and service actors. Based on it, an approach of product and service integration through lifecycles is proposed, intending to keep distinct product and service approaches for a better adoption on an organizational layer.

Services might be managed in a service-centered approach, as products are managed in a product-centered approach. This is achievable through product-centered and service-centered approaches for Information Systems, such as Product Lifecycle Management (PLM) or Service Lifecycle Management (SLM). In this paradigm of product and service integration, both PLM and SLM strongly interact with one another.

This allows service actors and product actors to carry on their core activities, with a better utilization of shared information. However, the convergence of products and services activities requires a transversal collaboration which is not natural, and might be supported by a collaborative framework, i.e. concepts, methods and tools supporting product and service integration [31]. In order to develop this framework, further explanations about Service Lifecycle Management is required. 
Service Management is a first approach answering the need of managing service information on its own, i.e. not based on product information. It aims at making accessible the information on pieces of equipment and task performed [31, 32]. According to Peruzzini et al., SLM can be defined after ISO 15704:2000 standard which specifies a generic entity/system lifecycle phases and its evolutions in time [31]. Service Lifecycle phases are: Service system definition, Requirements definition, Architecture design, System service implementation and Operation, and decommission.

Nevertheless, SLM is seldom defined in the literature. This paper proposes a vision of Service Lifecycle Management, which will to be applied in the automotive industry in the future. This proposition also endeavors to suggest how a product-centered PLM approach and a service-centered SLM approach could be integrated.

\section{Service Lifecycle Management proposal in convergence with Product Lifecycle Management}

\subsection{A model for PLM and SLM lifecycles}

Software editors as $\mathrm{PTC}^{1}$ provide application suites to manage services in a comprehensive manner. Remediating a pragmatic requirement to manage service information, these software solutions allow to harvest, process and monitor service information, but also to develop services (including new services) and a key factor of implementation is the integration with other information management approaches, especially PLM.

SLM can be defined similarly to PLM. Stark defines lifecycle of an offer (defined in its contribution under the paradigm of tangible and intangible offer), named "product manufacturer's view of the lifecycle" as following : Imagine, Define, Realize, Support/Service, Retire [33]. This definition of lifecycle is attributed to PLM and SLM approaches in Fig. 2. Product/service definition represents the first stages of a product/service development, which could for instance include need and requirements analysis. Product/service design means the technical and detailed design of a product/service. Implementation in Service Network is the stage in which all the entities are prepared to operate a service.

The benefit of this model lays on the fact that it keeps the distinction between product activities and service activities, as it is the case in many companies. Nevertheless, it does not show up the interactions between PLM and SLM. A first step into exploring PLM and SLM interactions is explained hereafter, based on previous PLM and SLM models.

\subsection{PLM and SLM parallel lifecycles model for Product-Service Integration}

In order to represent interactions between PLM and SLM, a linear model of PLM an SLM and their links is proposed in Error! Reference source not found.. On this model, interactions are identified

${ }^{1}$ http://www.ptc.com/ 


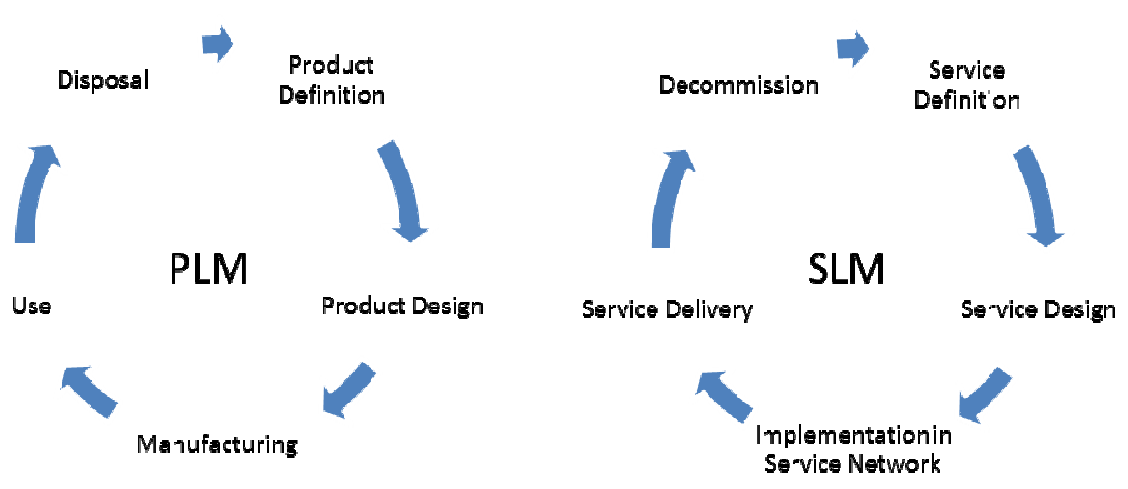

Fig. 2. PLM and SLM lifecycles

under two categories: major links and minor links. Major links represent substantial interactions between product and service activities. It reveals the necessity to construct products and services in strong collaboration. Minor links represent necessary but not predominant interactions, which can be realized on purpose, unlikely to be considered as mainly systematic. Each interaction is detailed hereafter:

1. Product Definition - Service Definition: In order to develop an integrated PSS offer, product and service definition stages might be developed with a strong collaboration in a paradigm of a product as a platform to operate services.

2. Product Design - Service Design: As for product and service definition, a major link might be observed for detailed design. The commonalities determined in

\section{PLM}

SLM
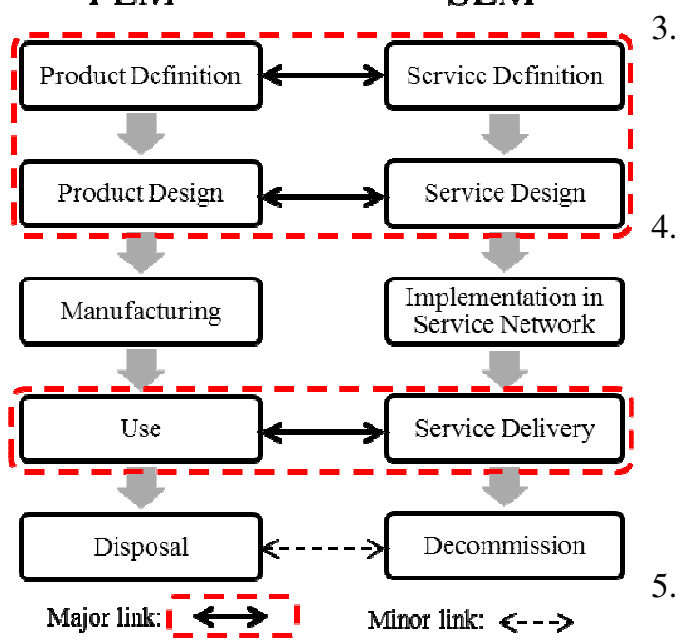

Fig. 3. Model of PLM and SLM parallel lifecycles for integration phase 1 echoe and are validated in phase 2.

3. Manufacturing - Implementation in Service Network: There are no direct interdependencies between manufacturing and implementation in service network.

. Use - Service Delivery: in a PSS paradigm, several particularities are notable. A product, which is a virtual platform to deliver services, maintains a relationship with service network during its use stage. Thus, information about product use can be harvested and has to be processed.

5. Disposal - Decomission: because of sustainability concerns, a better apprehension of PSS offer's End of Life might imply business models to take importance in disposal and decommission stages. 
Also, this model is shown as linear, in order to simplify the representation of PLM and SLM interactions. However the development of product or service is a non-linear process, and loops of development describe a notable aspect of it.

This interaction model needs to be completed with a deeper view of product and service activities convergence.

\section{Identification of the information to be shared between PLM and SLM related information systems, a focus on the automotive industry}

PLM and SLM approaches manipulate rich information from several entities concerned by the activities managed: technical data, applications, people, techniques, methods, equipment and resources, and production parameters. Product Data Management (PDM), Enterprise Resource Planning (ERP), Supply Chain Management (SCM) and Customer Relationship Management (CRM) are some of the applications frequently used in extended enterprises, representative of how disparate information could be in terms of nature. All the more accurate in the automotive industry, the stakes of product and service integration are one of the key strategic horizons. This historic manufacturing industry is being continuously economically challenged about products activities (development, manufacturing, selling). Additionally, new service actors emerge and develop solutions to answer new needs of car customers, which turns business models of the automotive industry towards more services, id est a servicization. This shift requires a car manufacturer to improve service activities, which are historically based on MRO operations, especially when he is naturally implementing a larger definition of services, still in a strong interaction with product activities.

The automotive industry is currently based on lifecycle approaches. More precisely, car manufacturers based their lifecycles approaches around the product. PLM proved its relevancy in this domain characterized by many actors, a global market, and multidisciplinary activities based on product development, manufacturing and selling. Main services operated by car manufacturers concern product maintenance, or financial services. The former category is naturally product-centered as defined in Tukker's classification (see Error! Reference source not found.); but the servicization of the automotive industry tends car manufacturers to develop services which are rather result-oriented or use-oriented. Additionally, car manufacturers present a prevailing characteristic concerning this servicization, which is the difficulty for their organizations to shift from an historic focus on product to a PSS orientation. The development of services will have to go along with a compliance of these large enterprises' organizational models, in which service and product activities are realized by different actors. This is why the purpose of this paper is to allow product actors and service actors to focus respectively on product and service activities, while a better integration of these activities is achieved. This outcome is attained via a product-centered PLM and a service-centered SLM, with strong interactions.

The model introduced in section 3 is a first vision of how to drive this integration, but deeper analysis is required to achieve PLM and SLM integration in the 
automotive industry, notably concerning the characterization of the interactions between these two approaches.

\subsection{Relations between product and service data}

First, information shared about products and services is complex to connect, as there is no bijections between product portfolio and service portfolio. In other terms, a product can support several different services, and similarly a service can be operated through several products. Furthermore, a product belongs to a system structure and can be either a system, either a sub-system or a component, which is also true for service. This complexity between product data and service data is illustrated in the following paragraph by the term of "product-service connections".

A main characteristic of the automotive industry is a high variety of products over a large amount of product instances. These products take place into a complex service network with many actors on the value chain. In this context of high variety, the customer desires to benefit from several criteria as quality of the product, price, services provided, customization offer, and delivery lead time [34]. He is not concerned about the service network, and he expects good value in its offer independently of the complexity of product-service connections. Also because of a poor product-service connection, a car manufacturer could face difficulties to master impact of product development and service development onto one another. A key to get a better mastering of interactions of products and services lays on the efficiency of product-service connection, allowing evaluating how a feature will impact the enterprise's business.

Also, illustrated with object orientation, a product instance is a living entity. In a PSS paradigm, the product-service offer is managed during all along its lifecycle, including use phase. The customer-provider contract is relationship-based, rather transaction-based for pure products sold once [10]. Or a product might be altered during its use phases, and information about its external ecosystem (including the user) determines how the provider will manage services accordingly. As a consequence, each instance of a product is correlated to unique information, best managed by the company which provides the offer. The PLM-SLM integration should be able to deal with this issue.

Afterwards, mechanisms for data exchange can be developed. For instance, nowadays in the automotive service network, a service operator might suffer from a poor product-service connection, making service operations harder to perform, resulting on inaccurate diagnosis, unsolved flaws, long time of operation and minor value of operation. Also, product development actors are aware that a design choice for a product affects service operations, through expert rules or exchanges with service development actors. Nevertheless, a more precise analysis of these impacts is enabled with mechanisms based on a better product-service connection.

\section{Conclusion}

Servicization of manufacturing industries is a shift towards a better integration of products and services in an offer named PSS. This integration requires a company to enable an effective collaboration between product and service actors. Product information and service information are of different kinds. To provide a PSS offer, the activities of a company is different between product development and service 
development and management. New type of data is to be harvested during the use phase, and processed in order to improve the PSS offer. Originally throughout maintenance services, companies developed services in lifecycle approaches to benefit from a better digital continuity and empower the advantages enabled by a PSS offer paradigm. Related to technical data, lifecycle approaches allows this convergence of products and services, but PLM approaches are questioned to answer use-oriented and result-oriented services. In this paper, a solution has been proposed with parallel lifecycle approaches for products and for services, namely PLM and SLM. Their convergence, necessary condition to operate a servicization, is analyzed and proposition of interactions between PLM and SLM are drafted, in order to present future corresponding challenges as a scientific and industrial implementation. The model of SLM is presented as a vision which is to be consolidated through a industrial case study. A generic model of PLM and SLM interactions should allow a discussion about PLM and SLM integration. This vision of PLM-SLM integration is to be confronted to the automotive industry example.

\section{References}

1. Oliva R., Kallenberg R., Olivia R., Kallenberg R (2003) Managing the transition from products to services. Int J Serv Ind Manag 14:160-172.

2. Wang PP., Ming XG., Li D., et al. (2011) Status review and research strategies on productservice systems. Int J Prod Res 49:6863-6883.

3. Homburg C., Garbe B (1999) Towards an Improved Understanding of Industrial Services: Quality Dimensions and Their Impact on Buyer-Seller Relationships. J Business-to-bus Mark 6:39-71.

4. Mont O (2002) Clarifying the concept of product-service system. J Clean Prod 10:237-245.

5. Goedkoop MJ., Van Halen CJG., Te Riele HRM., Rommens PJM (1999) Product Service systems, Ecological and Economic Basics

6. Manzini E., Vezzoli C (2003) A strategic design approach to develop sustainable product service systems: examples taken from the "environmentally friendly innovation" Italian prize. J Clean Prod 11:851-857.

7. Wong MTN (2004) Implementation of innovative product service systems in the consumer goods industry.

8. Baines TS., Braganza A., Kingston J., et al. (2009) State-of-the-art in product servicesystems. Proc. Inst. Mech. Eng. Part B J. Eng. Manuf. pp 1543-1552

9. Boehm M., Thomas O (2013) Looking beyond the rim of one's teacup: A multidisciplinary literature review of Product-Service Systems in Information Systems, Business Management, and Engineering \& Design. J Clean Prod 51:245-250.

10. Mahut F., Daaboul J., Bricogne M., Eynard B (2014) Survey on Product-Service System applications in the automotive industry. Ottawa

11. Pezzotta G., Pinto R., Pirola F., Ouertani M-Z (2014) Balancing Product-service Provider's Performance and Customer's Value: The SErvice Engineering Methodology (SEEM). Procedia CIRP. pp 50-55

12. Williams A (2006) Product-service systems in the automotive industry: the case of microfactory retailing. J Clean Prod 14:172-184.

13. Saaksvuori A., Immonen A (2008) Product Lifecycle Management, Springer Berlin Heidelberg.

14. Eynard B., Gallet T., Roucoules L., Ducellier G (2006) PDM system implementation based on UML. Math Comput Simul 70:330-342. 
15. Le Duigou J., Bernard A., Perry N (2012) Framework for Product Lifecycle Management integration in Small and Medium Enterprises Networks. Comput Aided Des Appl. pp 1-14.

16. Lee SG., Ma Y-S., Thimm GL., Verstraeten J (2008) Product lifecycle management in aviation maintenance, repair and overhaul. Comput Ind 59:296-303.

17. Bricogne M., Troussier N., Rivest L., Eynard B (2011) PLM perspectives in mechatronic systems design. Adv Prod Manag Syst 110.

18. Müller P., Muschiol M., Stark R (2012) PLM-based Service Data Management in Steam Turbine Business. In: Rivest L, Bouras A, Louhichi B (eds) Prod. Lifecycle Manag. Towar. Knowledge-Rich Enterp. Springer Berlin Heidelberg, pp 170-181

19. Shukla SK., Kumar S., Selvaraj P., Rao VS (2015) Maintenance management system for a defence aircraft development programme. Int J Prod Lifecycle Manag 8:65-79.

20. Aurich JC., Fuchs C., Wagenknecht C (2006) Life cycle oriented design of technical Product-Service Systems. J Clean Prod 14:1480-1494.

21. Tomiyama T (2001) Service engineering to intensify service contents in product life cycles. Proc. Second Int. Symp. Environ. Conscious Des. Inverse Manuf. IEEE Comput. Soc, pp 613-618

22. Sakao T., Shimomura Y (2007) Service Engineering: a novel engineering discipline for producers to increase value combining service and product. J Clean Prod 15:590-604.

23. Tukker A (2004) Eight types of product-service system: eight ways to sustainability? Experiences from SusProNet. Bus Strateg Environ 13:246-260.

24. Morelli N (2006) Developing new product service systems (PSS): methodologies and operational tools. J Clean Prod 14:1495-1501. doi: 10.1016/j.jclepro.2006.01.023

25. Shimomura Y., Arai T (2009) Service Engineering - Methods and Tools for Effective PSS Development. Introd. to Prod. .... pp 113-135

26. Maxwell D., Sheate W., van der Vorst R (2006) Functional and systems aspects of the sustainable product and service development approach for industry. J Clean Prod 14:14661479.

27. Alonso-Rasgado T., Thompson G., Elfström B-O (2004) The design of functional (total care) products. J Eng Des 15:515-540.

28. Isaksson O., Larsson TC., Rönnbäck AÖ (2009) Development of product-service systems: challenges and opportunities for the manufacturing firm. J Eng Des 20:329-348.

29. Gebauer H., Fleisch E (2007) An investigation of the relationship between behavioral processes, motivation, investments in the service business and service revenue. Ind Mark Manag 36:337-348.

30. Peruzzini M., Germani M., Marilungo E (2014) Product-Service Lifecycle Management in Manufacturing: An Industrial Case Study. In: Fukuda S, Bernard A, Gurumoorthy B, Bouras A (eds) Prod. Lifecycle Manag. a Glob. Mark. 11th IFIP WG 5.1 Int. Conf. PLM 2014, Yokohama, Japan, July 7-9, 2014, Revis. Sel. Pap. Springer Berlin Heidelberg, Yokohama, pp 445-454

31. Peruzzini M., Germani M., Favi C (2012) Shift from PLM to SLM: A method to support business requirements elicitation for service innovation. In: Rivest L, Bouras A, Louhichi B (eds) Prod. Lifecycle Manag. Towar. Knowledge-Rich Enterp. IFIP WG 5.1 Int. Conf. PLM 2012, Montr. QC, Canada, July 9-11, 2012, Revis. Sel. Pap., Springer. Springer Berlin Heidelberg, Montreal, pp 111-123

32. Keller G., Detering S (1995) Process-Oriented Modeling and Analysis of Business Processes using the R/3 Reference Model. In: Bernus P, Nemes L (eds) Model. Methodol. Enterp. Integr. Springer US, Queensland, Australia, pp 69-87

33. Stark J (2011) Product Lifecycle Management, Springer London, pp 1-16

34. Daaboul J., Da Cunha C., Bernard A., Laroche F (2011) Design for mass customization: Product variety vs. process variety. CIRP Ann - Manuf Technol 60:169-174. 